\title{
Pierre MICHON, Les Onze
}

Lagrasse, éditions Verdier, 2009, 137 p., ISBN 978-2-86432-552-9, $14 €$

\section{Serge Aberdam}

\section{(2) OpenEdition}

\section{Journals}

\section{Édition électronique}

URL : https://journals.openedition.org/ahrf/11545

DOI : 10.4000/ahrf.11545

ISSN : 1952-403X

Éditeur :

Armand Colin, Société des études robespierristes

\section{Édition imprimée}

Date de publication : 1 octobre 2009

Pagination : 167-168

ISBN : 978-2-200-92560-4

ISSN : 0003-4436

\section{Référence électronique}

Serge Aberdam, «Pierre мıсном, Les Onze », Annales historiques de la Révolution française [En ligne], 358 | octobre-décembre 2009, mis en ligne le 01 octobre 2012, consulté le 23 avril 2022. URL : http:// journals.openedition.org/ahrf/11545 ; DOI : https://doi.org/10.4000/ahrf.11545 
Pierre Michon, Les Onze, Lagrasse, éditions Verdier, 2009, 137 p., ISBN 978-2-86432-552-9, $14 €$.

Avec ce roman, Pierre Michon semble se saisir à pleines mains du mythe d'entre les mythes, car il ne traite pas ici de la commission des Onze, dont le rôle se borna à rédiger la Constitution de 1795, ou de l'instance secrète emblématique de la Sérénissime, mais bien du Comité de salut public de 1794. Il imagine qu'un contemporain de David aurait pu, aurait dû, peindre une représentation du Grand comité, un tableau qui donc aurait pu, aurait dû, exister et dont le Louvre aurait pu, aurait dû, être la destination finale, précisément au pavillon de Flore - de l'Égalité - où siégea le Comité.

Pas question de peinture allégorique ou symbolique, mais d'un portrait collectif, « fait d'hommes, dans cette époque où les tableaux étaient faits de vertus » (p. 44). Cette simplicité, justement, aurait-elle été compatible avec une toile de «quatre mètres trente sur un peu moins de trois mètres ", pour une sorte de portrait, même de groupe, dont nous savons bien que les contemporains ne le concevaient pas encore dans le cadre de la grande peinture, de la peinture d'histoire ? Le Serment du jeu de Paume célèbre un geste fondateur précis, et sa galerie de portraits y est subordonnée autant qu'elle y trouve son ordonnancement. Figurer collectivement le Comité comme tel aurait laissé supposer qu'il exerçait le pouvoir hors d'une mission reçue de la Convention, d'un mandat régulièrement renouvelé, d'une formalité indispensable, devenue rapidement une insupportable contrainte... Mais qu'importe, puisque c'est de cette fiction qu'a besoin Michon pour nous conter son histoire, celle de François-Élie Corentin, peintre inventé du tableau inventé, de sa généalogie inventée, de son apprentissage inventé et de sa place inventée parmi les plus grands - dont il faut bien alors modifier un peu la hiérarchie... !

Le trait vise parfois trop loin: "Soyons bas un instant, parlons politique » (p. 93), mais la commande, puisque c'en est bien sûr une, a le mérite logique de s'inscrire dans une sorte de police d'assurance, souscrite en février 1794 par quelques membres du Comité, avec d'autres commanditaires, dans l'espoir qu'elle aura son efficacité lorsque viendront les 
issues finales et fatales : le mécanisme imaginé n'est pas sans pertinence. En regard, Michon cherche à éclairer « Cette période qui est comme le comble de l'Histoire, et que par conséquent on appelle très justement la Terreur », et la mêlée des partis. Il oscille entre définitions politiques ou sociales et figurations éternelles du désordre : « La mère des monstres, les meutes du malheur, les mégères des deux sexes, l'huile sur le feu, le sel sur la plaie - les meutes plaintives et tueuses de la plèbe éternelle, aboyant... ». Dans la lignée des Vies minuscules, la force de son évocation de ceux qu'il appelle les Limousins, de la misère des sans grade, des itinéraires impossibles et des rares ascensions force cependant l'admiration. À sa façon, Michon traite d'abord d'histoire sociale.

Le tout est narré par un anonyme, sorte de guide omniscient ou de gardien inspiré qui s'affairerait à formuler - à faire comprendre - ce que le tableau des Onze ne dirait plus à un visiteur moderne, obsédé peut-être par sa renommée de «tableau le plus célèbre du monde » (p. 113), pour cela placé dans la « chambre terminale du Louvre, le saint des saints, sous la vitre blindée de cinq pouces » en haut du pavillon de Flore. On conçoit que Michon ne projette pas une simple fiction, une hypothèse unique, mais, de proche en proche, déforme subtilement toutes choses, par contagion discrète. David est un peintre secondaire, son Marat est resté à Versailles (p. 133) ; la Joconde fait partie des tableaux dont la renommée a souffert de la concurrence des Onze et les bâtiments du Louvre lui-même ont évolué bien différemment de ceux que nous connaissons. La présentation se cale d'ailleurs sur des pages célèbres - et fictives - de Michelet qu'il devient logiquement nécessaire de critiquer sur le mode d'une érudition fictive. Les déformations naissent les unes des autres, sans qu'on sache toujours très bien en fin de compte si c'est par nécessité logique ou bien si, au contraire, ce sont des envies de l'auteur qui refaçonnent un monde dont le tableau supposé ne serait que la pointe avancée. La Révolution française, en tout cas, ne s'en sort pas comme un objet classé, mais au contraire comme la manifestation ardente des forces les plus fondamentales de l'histoire humaine. Surprenant. 